\title{
Role of miR-214 in modulating proliferation and invasion of human colon cancer SW620 cells
}

\author{
HAIYING NIE ${ }^{1 *}$, DANDAN NIE ${ }^{2 *}$ and LAN MEN ${ }^{3}$ \\ ${ }^{1}$ Department of Vascular Surgery, China-Japan Union Hospital of Jilin University, Changchun, Jilin 130033; \\ ${ }^{2}$ Jilin Entry-Exit Inspection and Quarantine Bureau, Changchun, Jilin 130062; ${ }^{3}$ Department of Gastrointestinal Medicine, \\ China-Japan Union Hospital of Jilin University, Changchun, Jilin 130033, P.R. China
}

Received March 27, 2018; Accepted September 14, 2018

DOI: $10.3892 / \mathrm{ol} .2018 .9521$

\begin{abstract}
This study investigated the role of miR-214 in modulating proliferation and invasion of human colon cancer SW620 cells. Fifty-five patients with colon cancer who were treated in China-Japan Union Hospital of Jilin University from March 2014 to March 2015 were enrolled into this study. Their cancer and corresponding paracancerous tissues were collected and the expression levels of miR-214 were determined by RT-qPCR. A miR-214 expression vector was constructed. SW620 cells were transfected with the miR-214 expression vector and a blank vector. Cells transfected with the miR-214 expression vector were assigned to the miR-214 positive group and cells transfected with the blank vector were assigned to the miR-214 negative group. Cell proliferation, invasion and apoptosis were assessed by MTT assay, Transwell migration assay and TUNEL apoptosis assay, respectively. The RT-qPCR results showed that the expression level of miR-214 in colon cancer tissue, as well as in miR-214 negative cells, was significantly lower than that in paracancerous tissue $(\mathrm{P}<0.05$ for both). In cell comparison, the expression level of miR-214 in the miR-214 positive group was significantly higher than that in the miR-214 negative group $(0.483 \pm 0.001$ vs. $0.172 \pm 0.001$; $\mathrm{P}<0.05)$. The proliferation level of SW620 cells in the miR-214 positive group was lower than that in the miR-214 negative group $(\mathrm{P}<0.05)$. The Transwell migration assay indicated that there were less cells penetrating the membrane in the miR-214 positive group than in the miR-214 negative group $(\mathrm{P}<0.05)$. In addition, The apoptosis rate of cells in the miR-214 negative group was significantly lower than that in the miR-214 positive group $(\mathrm{P}<0.05)$. Finally, the low expression of miR-214
\end{abstract}

Correspondence to: Dr Lan Men, Department of Gastrointestinal Medicine, China-Japan Union Hospital of Jilin University, 126 Xiantai Street, Changchun, Jilin 130033, P.R. China

E-mail:mpd9ur@163.com

*Contributed equally

Key words: miR-214, colon cancer, SW620, proliferation, apoptosis, invasion was found in colon cancer, indicating that miR-214 is a cancer suppressor playing an opposing role in colon cancer onset and progression. Therefore, miR-214 can promote apoptosis of colon cancer cells SW620 by inhibiting their proliferation and invasion.

\section{Introduction}

Colon cancer is the most common malignant tumor of the digestive tract. It often occurs among adults aged above 40 years with a male-to-female ratio of 2-3:1. Colon cancer is a leading cause of cancer deaths worldwide $(1,2)$. With the improvement of the living standards and diet level, the incidence of colon cancer has been increasing year by year $(3,4)$. Like other cancers, the exact cause and pathogenesis of colon cancer remain unclear (5). The biological behavior of colon cancer is complex. Early screening, timely detection and treatment can effectively improve the survival rate of patients (6). Therefore, it is of great significance to explore the pathogenesis of colon cancer and look for new biological markers and therapeutic targets.

MicroRNAs (miRNAs) are widely expressed in eukaryotic organisms, regulating cell proliferation, differentiation and apoptosis. Aberrations in the process of miRNA biosynthesis were associated with a variety of pathophysiological processes $(7,8)$. In recent years, many studies have suggested that miR-214 was abnormally expressed in many malignant tumors such as ovarian cancer (9) and prostate cancer (10). However, the association of miR-214 with colon cancer has rarely been reported.

In this study, the expression levels of miR-214 in cancer and paracancerous tissues collected from patients with colon cancer were analyzed. The role of miR-214 in modulating proliferation and invasion of human colon cancer SW620 cells was explored as well. The goal of this study was to provide a new theoretical basis for the screening, diagnosis and treatment of colon cancer.

\section{Materials and methods}

General data. A total of 55 patients with colon cancer were enrolled in this study and they were treated in China-Japan Union Hospital of Jilin University (Changchun, China) from 
March 2014 to March 2015. Their cancer and corresponding paracancerous tissues were collected. The patients, including 31 males and 24 females, were aged 35-70 years with an average age of $55.43 \pm 12.75$ years. Patients who were pathologically diagnosed with colon cancer and met the following criteria were included in this study: i) without liver, kidney and other organ dysfunction before surgery; and ii) without bleeding and clotting disorders before surgery. Patients who met the following criteria were excluded from this study: i) being treated prior to this study; ii) with too large tumor; and iii) with other diseases such as lung or chest wall diseases.

This study was approved by the Ethics Committee of China-Japan Union Hospital of Jilin University. The patients or their families signed an informed consent.

Methods. Human colon cancer SW620 cells were purchased from Shanghai Beinuo Biotechnology Co., Ltd. (Shanghai, China) and cultured in Leibovitz's L-15 medium purchased from Changzhou Beiyuanxin Biotechnology Co., Ltd. (Jiangsu, China). The cell culture was maintained at constant $37^{\circ} \mathrm{C}$ and $\mathrm{pH}$ 6.8-7.4 in an incubator supplied with $5 \% \mathrm{CO}_{2}$. A miR-214 expression vector was constructed by Shanghai GenePharma Co., Ltd. (Shanghai, China). The constructed miR-214 expression vector (miR-214 positive group) and blank vector (miR-214 negative group) were cultured, respectively, with trypsin-digested human colon cancer cells SW620 in Leibovitz's L-15 medium at $37^{\circ} \mathrm{C}$ in an incubator supplied with $5 \% \mathrm{CO}_{2}$ for $24 \mathrm{~h}$. After transfection, the cells in the two groups were subjected to analytical experiments.

Total RNA extraction from tissues. Total RNA in cancer and paracancerous tissues was extracted by using TRIzol reagent purchased from Shanghai Mingjing Biotech Co., Ltd. (Shanghai, China), following the instructions contained in the TRIzol kit. The concentration and purity of the extracted RNA were measured with an MD1000 Microscale UV Spectrophotometer manufactured by Thmorgan Biotechnology Co., Ltd. (Beijing, China). Integrity of the RNA was assessed by $3 \%$ agarose gel electrophoresis. The gel electrophoresis set was purchased from Shanghai Jingke Science and Technology Co., Ltd. (Shanghai, China).

$m i R-214 R T-q P C R$ assay. Synthesis of cDNA from the extracted total miRNA was performed, via reverse transcription, at $37^{\circ} \mathrm{C}$ for $45 \mathrm{~min}$ and $95^{\circ} \mathrm{C}$ for $5 \mathrm{~min}$ by using the fluorescence quantitative PCR kit purchased from Thermo Fisher Scientific Co., Ltd. (Shanghai, China) following the instructions contained in the kit. Total volume of the PCR amplification reaction system was $20 \mu$ l. The PCR reaction was performed as follows: pre-denaturation at $95^{\circ} \mathrm{C}$ for $10 \mathrm{~min}$, 40 cycles of $95^{\circ} \mathrm{C}$ for $10 \mathrm{sec}$ (denaturation), $60^{\circ} \mathrm{C}$ for $20 \mathrm{sec}$ (annealing), and $72^{\circ} \mathrm{C}$ for $10 \mathrm{sec}$ (extension), followed by extension at $72^{\circ} \mathrm{C}$ for $5 \mathrm{~min}$ at the end of the cycles. U6 was used as the reference gene. All samples were run in triplicate. The results were analyzed by using the $2^{-\Delta \Delta \mathrm{Cq}}$ method (11). The RT-qPCR primers were synthesized by Suzhou Synbio Technologies Co., Ltd. (Suzhou, China). The primer sequences were as follows: for miR-214 the forward sequence was 5'-AGCCACATCGCT CAGACA-3', and the reverse sequence was 5'-CAGACGAGG CTCCGTGGT-3'; for U6 the forward sequence was 5'-CGCT TCGGCAGCACATATAC-3', and the reverse sequence was 5'-TTCACGAATTTGCGTGTCAT-3'.

In vitro proliferation of SW620 cells assessed by MTT assay. The transfected human colon cancer SW620 cells in the miR-214 positive and negative groups were prepared into a single cell suspension, followed by routine seeding in a 96-well cell culture plate. After culturing for $6 \mathrm{~h}, 20 \mu \mathrm{l}$ of MTT solution $(5 \mathrm{mg} / \mathrm{ml})$ was added to a portion of the cultured cells, and incubation was continued at $37^{\circ} \mathrm{C}$ for $4 \mathrm{~h}$. After sucking away the supernatant containing the medium and reagents, DMSO was added, followed by shaking on a rocking platform shaker for $15 \mathrm{~min}$. The absorbance at a wavelength of $570 \mathrm{~nm}$ was measured by using an ELISA reader. After culturing for 12, 24, 48 and $72 \mathrm{~h}$, the above MTT assay was repeated to obtain data at different time-points. The MTT assay kits were purchased from Shanghai LMAI Bio Co., Ltd (Shanghai, China).

Transwell in vitro migration assay. Single cell suspensions of transfected SW620 cells in the miR-214 positive and negative groups were prepared and seeded in triplicate $\left(\sim 1 \times 10^{5}-1 \times 10^{6}\right.$ cells per well) into Transwell upper chambers, respectively. The number of cells passing through the membrane in each well was counted two weeks later. The Transwell plates were purchased from Shanghai Yuanzi Biotechnology Co., Ltd. (Shanghai, China).

TUNEL apoptosis assay. After culturing for $48 \mathrm{~h}$, the cells (approximately $5 \times 10^{7}$ cells $/ \mathrm{ml}$ ) were fixed in $4 \%$ neutral formalin for $10 \mathrm{~min}$ at room temperature. Following removal of the supernatant, the fixed cells were washed twice with PBS for 5 min each. The cells were then incubated in PBS containing $2 \%$ hydrogen peroxide for $5 \mathrm{~min}$ at room temperature. Following removal of the supernatant, the fixed cells were washed with PBS twice for $5 \mathrm{~min}$ each, and were then stained by using TUNEL kits (Shanghai Runwell Technology Co., Ltd., Shanghai, China) according to the protocol contained in the kit. The number of TUNEL-positive cells in five 400 -fold fields of view was counted by using the image analysis software Image-pro Plus 5.0. The cumulative optical density value represented the total number of TUNEL positive cells. The measurement was repeated three times.

Statistical analysis. The statistics software SPSS 19.0 (AsiaAnalytics Formerly SPSS China, Shanghai, China) was used for statistical analysis. The $\chi^{2}$ test was applied to rate comparison. Measurement data were expressed as mean \pm standard deviation. The t-test was used for comparison of data that were normally distributed. $\mathrm{P}<0.05$ was considered to indicate a statistically significant difference.

\section{Results}

Levels of miR-214 in colon cancer and paracancerous tissues as well as in SW620 cells. The levels of miR-214 in colon cancer and paracancerous tissues, as well as in SW620 cells, were measured by RT-qPCR. As shown in Fig. 1, the expression levels of miR-214 in the colon cancer tissue $(0.203 \pm 0.001)$ and in SW620 cells in the miR-214 negative group $(0.172 \pm 0.001)$ were comparable $(\mathrm{P}>0.05)$, and both were significantly lower 


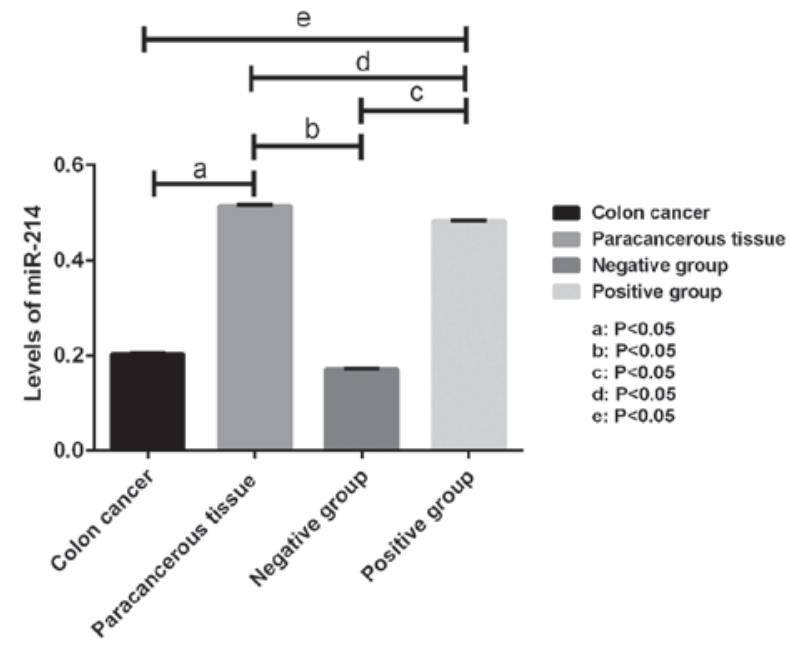

Figure 1. Levels of miR-214 in colon cancer and paracancerous tissues and in human colon cancer SW620 cells measured by RT-qPCR. The RT-qPCR assay showed that the expression levels of miR-214 in colon cancer tissue $(0.203 \pm 0.001)$ and in SW620 cells in the miR-214 negative group $(0.172 \pm 0.001)$ were comparable $(P>0.05)$, and both were significantly lower than that in the paracancerous tissue $(0.515 \pm 0.002)$. The differences were statistically significant $(\mathrm{P}<0.05)$. The miR-214 expression level in SW620 cells in the miR-214 positive group $(0.483 \pm 0.001)$ was significantly higher than those in SW620 cells in the miR-214 negative group and in the cancer tissue, but was lower than that in paracancerous tissue $(\mathrm{P}<0.05)$.

Table I. Association of miR-214 expression level with clinicopathological characteristics by $\chi^{2}$ test.

\begin{tabular}{|c|c|c|c|c|}
\hline $\begin{array}{l}\text { Clinicopathological } \\
\text { characteristics }\end{array}$ & n $(\%)$ & $\begin{array}{c}\text { miR-214 } \\
\text { level }\end{array}$ & $\chi^{2}$ & P-value \\
\hline Patient number & 55 & $0.203 \pm 0.001$ & & \\
\hline Sex & & & 1.087 & 0.282 \\
\hline Male & $31(56.36)$ & $0.212 \pm 0.003$ & & \\
\hline Female & $24(43.74)$ & $0.206 \pm 0.007$ & & \\
\hline Age (years) & & & 1.174 & 0.246 \\
\hline$<45$ & $19(34.55)$ & $0.203 \pm 0.002$ & & \\
\hline$\geq 45$ & $36(65.45)$ & $0.211 \pm 0.005$ & & \\
\hline Clinical stage & & & 0.924 & 0.359 \\
\hline $\mathrm{T} 1 / \mathrm{T} 2$ & $20(33.36)$ & $0.203 \pm 0.009$ & & \\
\hline T3/T4 & $35(62.64)$ & $0.207 \pm 0.001$ & & \\
\hline Invasion depth & & & 1.962 & 0.055 \\
\hline Muscularis & $14(25.45)$ & $0.214 \pm 0.005$ & & \\
\hline Serosa & $41(74.55)$ & $0.232 \pm 0.001$ & & \\
\hline Differentiation & & & 1.394 & 0.169 \\
\hline Well & 43 (78.18) & $0.229 \pm 0.006$ & & \\
\hline $\begin{array}{l}\text { Moderately and } \\
\text { poorly }\end{array}$ & $12(21.82)$ & $0.214 \pm 0.007$ & & \\
\hline Lymph node status & & & 1.998 & 0.051 \\
\hline Metastasis & $32(58.18)$ & $0.221 \pm 0.006$ & & \\
\hline No metastasis & $23(41.82)$ & $0.202 \pm 0.003$ & & \\
\hline $\begin{array}{l}\text { Histological } \\
\text { classification }\end{array}$ & & & 34.42 & $<0.001$ \\
\hline $\begin{array}{l}\text { Mucinous } \\
\text { carcinoma }\end{array}$ & $15(27.27)$ & $0.116 \pm 0.007$ & & \\
\hline $\begin{array}{l}\text { Non-mucinous } \\
\text { carcinoma }\end{array}$ & $40(72.73)$ & $0.303 \pm 0.004$ & & \\
\hline
\end{tabular}

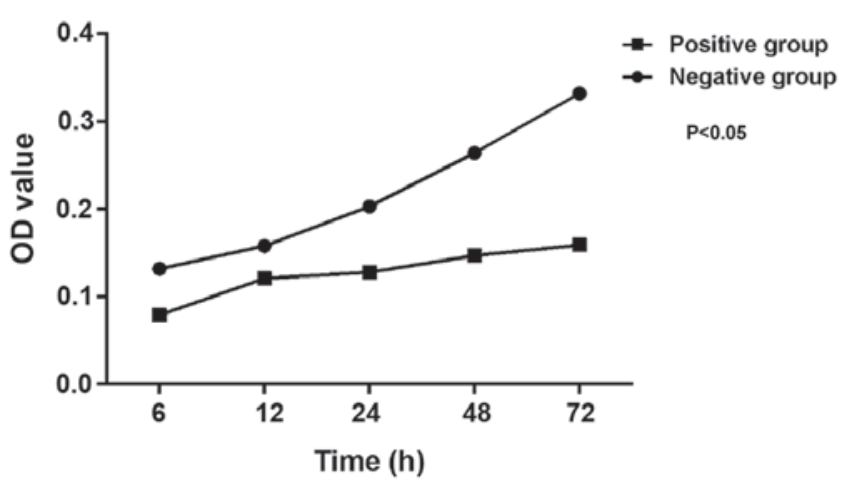

Figure 2. Proliferation of human colon cancer SW620 cells assessed by MTT assay. The MTT assay showed that the OD values of cells in the miR-214 positive group were lower than those in the miR-214 negative group at five time-points of $6,12,24,48$ and $72 \mathrm{~h}$, indicating that the proliferation rate of cells in the miR-214 positive group was lower due to the higher miR-214 level. The difference was statistically significant $(\mathrm{P}<0.05)$. OD, optical density.

than that in the paracancerous tissue $(0.515 \pm 0.002)$. The differences were statistically significant $(\mathrm{P}<0.05)$. The miR-214 expression level in SW620 cells in the miR-214 positive group $(0.483 \pm 0.001)$ was significantly higher than those in SW620 cells in the miR-214 negative group and in cancer tissue, but was lower than that in paracancerous tissue $(\mathrm{P}<0.05)$.

Association of miR-214 expression level with clinical pathological characteristics. The expression level of miR-214 was not associated with the patient's sex, age, clinical stage, depth of tumor invasion, degree of differentiation, or lymph node metastasis $(\mathrm{P}>0.05)$. However, the miR-214 level was associated with histological classification of colon cancer. As shown in Table I, the expression level of miR-214 in mucinous carcinoma was significantly lower than that in the non-mucinous carcinoma $(\mathrm{P}<0.05)$.

Proliferation of SW620 cells assessed by MTT assay. The proliferation of SW620 cells in the miR-214 positive and negative groups was determined by MTT assay. As shown in Fig. 2, the optical density (OD) values of cells in the miR-214 positive group were lower than those in the miR-214 negative group at five time-points of $6,12,24,48$ and $72 \mathrm{~h}$, indicating that the proliferation rate of cells in the miR-214 positive group was lower due to the higher miR-214 level. The difference was statistically significant $(\mathrm{P}<0.05)$.

Invasion of SW620 cells measured by Transwell in vitro migration assay. The invasiveness of SW620 cells in the miR-214 positive and negative groups was measured by Transwell in vitro migration assay. As shown in Fig. 3, the number of SW620 cells passing through the membrane in the miR-214 positive group $(93.17 \pm 11.02)$ was substantially less than that $(167.32 \pm 12.15)$ in the miR-214 negative group $(\mathrm{P}<0.05)$.

Apoptosis of SW620 cells measured by TUNEL apoptosis assay. Apoptosis of SW620 cells in the miR-214 positive and negative groups was measured by TUNEL apoptosis assay. As shown in Fig. 4, the apoptosis rate of cells in the miR-214 negative group (18.36 $\pm 1.35 \%)$, was significantly lower than 


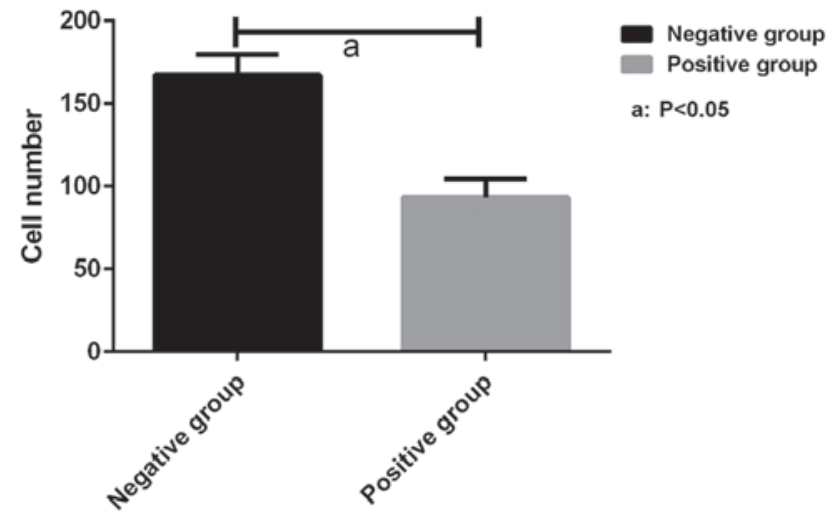

Figure 3. Invasion of human colon cancer SW620 cells measured by Transwell in vitro migration assay. The Transwell assay showed that the number of SW620 cells passing through the membrane in the miR-214 positive group $(93.17 \pm 11.02)$ was substantially less than that $(167.32 \pm 12.15)$ in the miR-214 negative group $(\mathrm{P}<0.05)$.

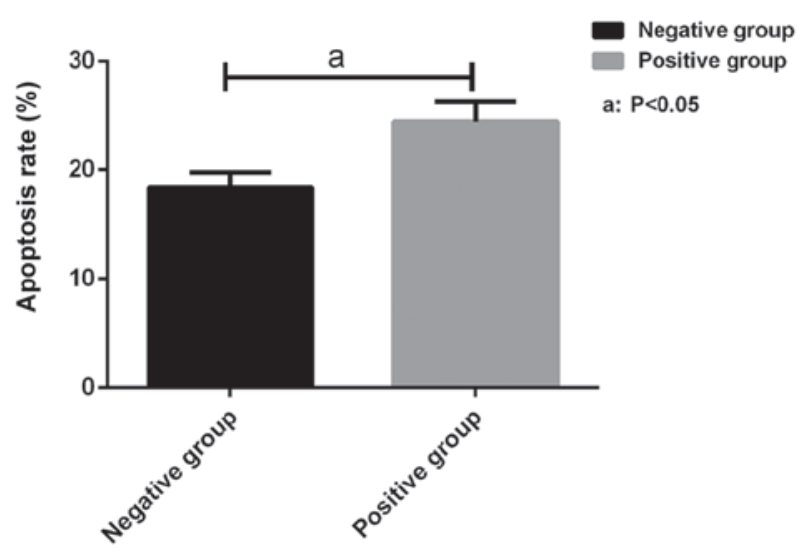

Figure 4. Apoptosis of human colon cancer SW620 cells measured by TUNEL apoptosis assay. TUNEL apoptosis assay showed that the apoptosis rate of cells in the miR-214 negative group was significantly lower than that in the miR-214 positive group. The difference was statistically significant $(\mathrm{P}<0.05)$

$(24.41 \pm 1.81 \%)$ in the miR-214 positive group. The difference was statistically significant $(\mathrm{P}<0.05)$.

\section{Discussion}

Research focusing on miRNAs represents one of the most popular topics in cancer research. The aberrant expression of miRNAs can modify the expression of tumor-related genes, impacting tumor onset and progression $(12,13)$. Qiang et al reported that plexin $\mathrm{B} 1$ can promote proliferation and invasion of human cervical cancer HeLa cells, and the plexin B1 level was found to be negatively correlated with the miR-214 level in both cervical cancer tissue and HeLa cells (14). Therefore, it was postulated that upregulation of the miR-214 expression can inhibit HeLa cell proliferation, migration and invasion. In this study, the expression levels of miR-214 in colon cancer and paracancerous tissue were evaluated aiming at exploring the relationship between miR-214 and colon cancer. In addition, the biological function of miR-214 on human colon cancer cells was investigated by using SW620 cells. It was found in this study that the expression level of miR-214 in colon cancer tissue was significantly lower than that in paracancerous tissue, suggesting that miR-214 may play a tumor-suppressing role in colon cancer as a tumor suppressor candidate gene. By analyzing any possible correlation between the miR-214 expression level and the patient's clinical characteristics, it was found that the difference in the miR-214 expression level was statistically significant only between the two histological types. Specifically, the miR-214 level in non-mucinous colon cancer was significantly higher than that in mucinous colon cancer. There were no statistically significant differences in sex, age and colon cancer clinical stage among the subjects. The association of miR-214 with colon cancer has rarely been reported. However, miR-214 was reported to be either upregulated or downregulated in other types of cancer, playing a tumor-suppressing or tumor-promoting role. For example, miR-214 was downregulated in cutaneous squamous cell carcinoma (15), whereas it was upregulated in nasopharyngeal carcinoma (16). Therefore, it is possible that miR-214 may be involved in the onset of colon cancer.

In order to further study the expression of miR-214 in colon cancer and its biological effect on colon cancer, human colon cancer SW620 cells were transfected with a miR-214 expression vector. The transfected cells were cultured and used in the study of miR-214 biological effects by MTT proliferation, Transwell in vitro migration and TUNEL apoptosis assays. It was found in this study that the expression level of miR-214 was also lower in SW620 cells transfected with a blank vector than that in the paracancerous tissue. After upregulating miR-214 expression in SW620 cells by transfection with a miR-214 expression vector, the proliferation and invasiveness of SW620 cells were inhibited while the apoptosis rate was increased compared with SW620 cells transfected with a blank vector. In literature, Huang et al reported that miR-214 was downregulated in esophageal squamous cell carcinoma and patients with lymph node metastases experienced even lower miR-214 level (17). Yang et al reported that miR-214 can modulate proliferation and invasion of gastric cancer cells (18). Li et al reported that downregulation of the miR-214 expression can promote metastases of intrahepatic cholangiocarcinoma (19). Wang et al reported that inhibition of miR-214 can attenuate proliferation of hepatocellular carcinoma (20). The findings in the above literature were similar to our results using SW620 cells. Therefore, it was postulated that miR-214 can inhibit proliferation and invasion of colon cancer cells. Huang et al also reported that miR-214 was associated with the pathological type and clinical stage of esophageal squamous cell carcinoma, as well as the patient's lymph node status (17). This was inconsistent with our findings in correlation analysis of the miR-214 expression level and clinical characteristics of patients. The reason may be related to different types of tumors being studied or limited number of subjects being enrolled in this study. The results in this study demonstrated that miR-214 was downregulated in colon cancer and was involved in modulation of proliferation and invasion of colon cancer cells.

Wang et al reported that miR-214 can enhance patients' sensitivity to the chemotherapeutic drug cisplatin by inhibiting the expression of Bcl212 in cervical cancer HeLa and C-33A cells (21). Xia et al reported that downregulation of miR-214 was associated with recurrence of hepatocellular carcinoma (22). The $\beta$-catenin signaling pathway in hepatocellular carcinoma was modulated by miR-214 directly or indirectly through targeting CTNNB1. Schwarzenbach et al reported that miR-214 
can be used as a marker in diagnosis of breast cancer (23). In this study, the role of miR-214 in diagnosis, treatment and prognosis of colon cancer was not explored due to certain limitations. In our future study, these questions will be addressed.

In conclusion, miR-214 was downregulated in colon cancer. It exhibited inhibitory effect in the onset of colon cancer as a tumor suppressor gene. The proliferation and invasion of colon cancer SW620 cells were attenuated by miR-214, while the apoptosis rate was increased. It is possible that miR-214 can be a new target in the treatment of colon cancer.

\section{Acknowledgements}

Not applicable.

\section{Funding}

No funding was received.

\section{Availability of data and materials}

The datasets used and/or analyzed during the present study are available from the corresponding author on reasonable request.

\section{Authors' contributions}

HN wrote the manuscript and extracted total RNA from tissues. DN performed the RT-qPCR. LM contributed to performing the MTT assay. All authors have read and approved the final manuscript.

\section{Ethics approval and consent to participate}

The study was approved by the Ethics Committee of ChinaJapan Union Hospital of Jilin University (Changchun, China). Patients who participated in this research, signed an informed consent and had complete clinical data.

\section{Patient consent for publication}

Not applicable.

\section{Competing interests}

The authors declare that they have no competing interests.

\section{References}

1. Llosa NJ, Cruise M, Tam A, Wicks EC, Hechenbleikner EM, Taube JM, Blosser RL, Fan H, Wang H, Luber BS, et al: The vigorous immune microenvironment of microsatellite instable colon cancer is balanced by multiple counter-inhibitory checkpoints. Cancer Discov 5: 43-51, 2015.

2. Kyu HH, Bachman VF, Alexander LT, Mumford JE, Afshin A, Estep K, Veerman JL, Delwiche K, Iannarone ML, Moyer ML, et al: Physical activity and risk of breast cancer, colon cancer, diabetes, ischemic heart disease, and ischemic stroke events: Systematic review and dose-response meta-analysis for the Global Burden of Disease Study 2013. BMJ 354: i3857, 2016.

3. de Sousa e Melo F, Kurtova AV, Harnoss JM, Kljavin N, Hoeck JD, Hung J, Anderson JE, Storm EE, Modrusan Z, Koeppen H, et al: A distinct role for $\mathrm{Lgr}^{+}$stem cells in primary and metastatic colon cancer. Nature 543: 676-680, 2017.
4. Abdel-Rahman WM, Faris ME and Peltomaki P: Molecular determinants of colon cancer susceptibility in the East and West. Curr Mol Med 17: 34-45, 2017.

5. Cayrefourcq L, Mazard T, Joosse S, Solassol J, Ramos J, Assenat E, Schumacher U, Costes V, Maudelonde T, Pantel K, et al: Establishment and characterization of a cell line from human circulating colon cancer cells. Cancer Res 75: 892-901, 2015.

6. Tie J, Wang Y, Tomasetti C, Li L, Springer S, Kinde I, Silliman N, Tacey M, Wong HL, Christie M, et al: Circulating tumor DNA analysis detects minimal residual disease and predicts recurrence in patients with stage II colon cancer. Sci Transl Med 8: 346ra92, 2016.

7. Tang S, Gao L, Kathleen K, Fink A, Kalvala A, Aguila B Otterson G, Villalonacalero M and Duan W: micoRNA in FA defective tumor. Cancer Res 77 (Suppl 13): Abst 4442, 2017.

8. Nieuwenhuizen L, de Groot PG, Grutters JC and Biesma DH: A review of pulmonary coagulopathy in acute lung injury, acute respiratory distress syndrome and pneumonia. Eur J Haematol 82: 413-425, 2009.

9. Wang Z, Yin H, Zhang Y, Feng Y, Yan Z, Jiang X, Bukhari I, Iqbal F, Cooke HJ and Shi Q: miR-214-mediated downregulation of RNF8 induces chromosomal instability in ovarian cancer cells. Cell Cycle 13: 3519-3528, 2014.

10. Srivastava A, Goldberger H, Dimtchev A, Ramalinga M, Chijioke J, Marian C, Oermann EK, Uhm S, Kim JS, Chen LN, et al: MicroRNA profiling in prostate cancer - the diagnostic potential of urinary miR-205 and miR-214. PLoS One 8: e76994, 2013.

11. Livak KJ and Schmittgen TD: Analysis of relative gene expression data using real time quantitative PCR and the 2( Delta Delta C(T)) Method. Methods 25: 402 408, 2001.

12. Ha M and Kim VN: Regulation of microRNA biogenesis. Nat Rev Mol Cell Biol 15: 509-524, 2014.

13. Agarwal V, Bell GW, Nam JW and Bartel DP. Predicting effective microRNA target sites in mammalian mRNAs. Elife 12: e05005, 2015.

14. Qiang R, Wang F, Shi LY, Liu M, Chen S, Wan HY, Li YX, Li X, Gao SY and Sun BC: Plexin-B1 is a target of miR-214 in cervical cancer and promotes the growth and invasion of HeLa cells. Int J Biochem Cell Biol 43: 632-641, 2011.

15. Yamane K, Jinnin M, Etoh T, Kobayashi Y, Shimozono N, Fukushima S, Masuguchi S, Maruo K, Inoue Y, Ishihara T, et al: Down-regulation of miR-124/-214 in cutaneous squamous cell carcinoma mediates abnormal cell proliferation via the induction of ERK. J Mol Med (Berl) 91: 69-81, 2013.

16. Deng M, Ye Q, Qin Z, Zheng Y, He W, Tang H, Zhou Y, Xiong W, Zhou M, Li X, et al: miR-214 promotes tumorigenesis by targeting lactotransferrin in nasopharyngeal carcinoma. Tumour Biol 34: 1793-1800, 2013.

17. Huang SD, Yuan Y, Zhuang CW, Li BL, Gong DJ, Wang SG, Zeng ZY and Cheng HZ: MicroRNA-98 and microRNA-214 post-transcriptionally regulate enhancer of zeste homolog 2 and inhibit migration and invasion in human esophageal squamous cell carcinoma. Mol Cancer 11: 51, 2012.

18. Yang TS, Yang XH, Wang XD, Wang YL, Zhou B and Song ZS: miR-214 regulate gastric cancer cell proliferation, migration and invasion by targeting PTEN. Cancer Cell Int 13: 68, 2013.

19. Li B, Han Q, Zhu Y, Yu Y, Wang J and Jiang X: Down-regulation of miR-214 contributes to intrahepatic cholangiocarcinoma metastasis by targeting Twist. FEBS J 279: 2393-2398, 2012.

20. Wang X, Chen J, Li F, Lin Y, Zhang X, Lv Z and Jiang J: miR-214 inhibits cell growth in hepatocellular carcinoma through suppression of $\beta$-catenin. Biochem Biophys Res Commun 428: $525-531,2012$.

21. Wang F, Liu M, Li X and Tang H: miR-214 reduces cell survival and enhances cisplatin-induced cytotoxicity via down-regulation of Bcl212 in cervical cancer cells. FEBS Lett 587: 488-495, 2013.

22. Xia H, Ooi LL and Hui KM: miR-214 targets $\beta$-catenin pathway to suppress invasion, stem-like traits and recurrence of human hepatocellular carcinoma. PLoS One 7: e44206, 2012.

23. Schwarzenbach H, Milde-Langosch K, Steinbach B, Müller V and Pantel K: Diagnostic potential of PTEN-targeting miR-214 in the blood of breast cancer patients. Breast Cancer Res Treat 134: 933-941, 2012.

This work is licensed under a Creative Commons Attribution-NonCommercial-NoDerivatives 4.0 International (CC BY-NC-ND 4.0) License. 